\title{
How can we help people to choose a method of contraception? The case for contraceptive decision aids
}

\author{
Rebecca S French, Kaye Wellings, Frances M Cowan
}

\section{Background}

Contraceptive decision-making is a complex process. In an ideal world, individuals would choose the best method of contraception for them by systematically weighing up its 'pros and cons', based on the importance they attach to criteria such as efficacy, safety and ease of use, the extent to which the available contraceptive options are able to meet these criteria, and accurate and reliable information on both. In practice, this is rarely the case. Methods tend to be chosen according to personal beliefs and preconceptions, with concerns about side effects and health risks, for example, often overestimated.' 'Medical intervention' can also affect people's decision-making. For example, the attitudes and beliefs of health care workers can influence the contraceptive options clients are presented with.

Few would disagree that women and men need a better understanding of the risks and benefits associated with different methods to make an informed choice. A choice well made is not only more likely to lead to correct and consistent use, but also to higher continuation rates. This has potential benefits for the individual, and also for public health more broadly. Analysing the impact of contraceptive discontinuation in 15 developing or transitional countries, Blanc and colleagues report that within a year of starting a new contraceptive method, $7-15 \%$ of women stopped using contraception for quality-related reasons. ${ }^{2}$ Preventing unplanned births consequent on discontinuation of contraception would have reduced the total fertility rate by an estimated $28-64 \%$. The case for developing interventions to improve sustained and correct use of methods acceptable to women (and men) is therefore strong.

\section{Role of decision aids}

To date, strategies to improve adherence and acceptability of contraceptives have met with little success. ${ }^{3}$ Inadequate understanding of the contraceptive decision-making process has been cited as one reason for the failure to develop effective interventions to reduce unplanned pregnancy and the spread of sexually transmitted infections (STIs). ${ }^{4}$ Decision aids may have a valuable role in this respect. Though they are increasingly used in the context of health care decision-making, they are rarely used in contraceptive settings. Decision aids are tools that provide a structured framework to systematically analyse the

\section{J Fam Plann Reprod Health Care 2009; 35(4): 219-220}

Department of Public Health and Policy, London School of Hygiene \& Tropical Medicine, London, UK

Rebecca S French, MSc, PhD, Senior Lecturer

Kaye Wellings, FRCOG, FFPH, Professor

Department of Infection \& Population Sciences, University College London, London, UK

Frances M Cowan, MSc, MD, Senior Lecturer

Correspondence to: Dr Rebecca French, Public and Environmental Health Research Unit, London School of Hygiene \& Tropical Medicine, Keppel Street, London WC1E 7HT, UK. E-mail: Rebecca.French@Ishtm.ac.uk available options and their possible outcomes to help the decision maker select the option that best takes account of their individual needs and values. ${ }^{5}$ Aids can adopt different approaches, from scenario planning to more structured approaches, such as decision analysis. They differ from health education material, such as information leaflets, in that they not only provide information, but also focus on the way in which it is received and processed by the individual and identify the costs and benefits attached to the decision. The decision maker is asked to consider the values they themselves associate with the costs and benefits, for example "How important is it that you don't get pregnant now?" or "How important is it to you that your method is free from side effects?". Individual beliefs and values surrounding sexual health vary enormously and generalising behavioural interventions across different populations can be problematic. A great benefit of decision aids is that they consider the individual user's preferences and priorities in their current circumstances, in relation to attributes of the different methods. They can be designed to take into account different levels of risk that may affect the 'best' contraceptive option for the user, for example, the chance of an 18-year-old woman with multiple partners acquiring an STI will be higher than a 35-year-old woman in a monogamous relationship.

\section{Case for decision aids}

The case for decision aids in helping people with their contraceptive decision-making can be made on a number of grounds.

- Most people are faced with decisions around fertility control and STI avoidance at some time in their life.

- For the individual, the repercussions of 'poor' contraceptive decisions can be long lasting and can have negative consequences on both health and social outcomes. At a societal level, 'poor' contraception decisions can have public health and cost implications.

- Traditional ways of delivering contraceptive care have had limited success in reducing poor sexual outcomes, particularly amongst young people.

- People often have insufficient knowledge about the range of contraceptive methods and their risks and benefits to be able to make an informed decision.

- People seeking contraception are generally 'healthy' so that a personal and social approach to care is more appropriate than adoption of a purely medical model.

Where decision aids have been used within contraceptive services there has been a positive effect on communication and decision-making. Studies have found that when used in consultations, decision aids are acceptable to users, clients are more involved in the decision-making process, and there is greater client/provider interaction and more information sharing. ${ }^{6-9}$ However, the evidence on the impact of these aids on long-term knowledge, contraceptive use and sexual health outcomes has not yet been established. 6,10 None of the contraceptive decision aid studies have used randomised controlled trials.

\section{Future research on decision aids}

The interest in decision aids has risen in tandem with the move away from paternalistic medicine to a more 
consumer-focused approach to health care. ${ }^{6}$ Consumer priorities are important influences on the success of decision aids, and may differ from those of the provider. In the few studies there are on the use of decision aids in the contraceptive context, the aid has been introduced during the consultation, a setting which may be identified as potentially problematic because of constraints on time and pressure for productivity. ${ }^{11}$ More time may be available before the clinical consultation; decision aids have as yet unexploited potential as pre-consultation tools. Alternately, there may be benefits to their use quite separately from the health care setting, and in this context the use of decision aids on Internet sites merits further exploration. Web-based decision tools are interactive, easily updated and able to hold individualised data. Field-testing is crucial to address contextual issues, in particular how decision aids can best be adapted and used in different cultural or service delivery settings. Well-designed studies on the impact decision aids have on initiation of contraceptive methods and on their sustained and correct use are needed.

Sex and decision theory are not obvious partners. Sex is for the most part not a time for 'rational' decision-making. Yet though sex may not be planned, contraceptive choice can be, and the role of decision aids in improving effective use of acceptable contraceptive methods warrants further investigation.

\section{Statements on funding and competing interests \\ Funding None identified.}

Competing interests None identified.

\section{References}

1 Edwards JE, Oldman A, Smith L, McQuay HJ, Moore RA. Women's knowledge of, and attitudes to, contraceptive

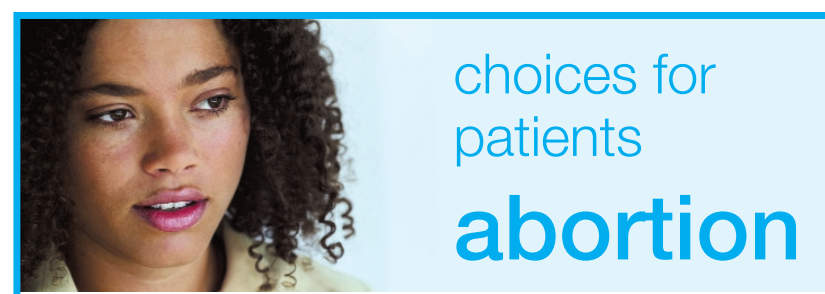

Dr Kate Worsley

Head of Medical Development - Marie Stopes International

Marie Stopes International sees over one third of all women seeking abortion services in England and Wales. As experts in this field they have pioneered and modernised abortion provision making them first choice amongst healthcare professionals. The service is always designed around the clients needs and convenience. An example of this is the recent development by the organisation of offering women the choice of having a telephone consultation where they can discuss their abortion options from the comfort of their own homes.

Medical abortion - currently one third of women between 4-9 weeks gestation having abortion choose the abortion pill. At Marie Stopes centres this has been simplified to just two visits.

Surgical abortion - women prefer a quick, convenient appointment and the majority are now choosing Marie Stopes one visit only appointments. A choice of anaesthesia is also offered by the organisation

A dedicated 24 hour aftercare line run by a team of expert nurses offers clients all the advice and support they need.

For more information call for a Marie Stopes International GP sexual health pack containing referral guidelines and client leaflets.

08451203644

www.mariestopes.org.uk

CONTRACEPTION • HEALTH SCREENING

STERILISATION • VASECTOMY • ABORTION effectiveness and adverse health effects. Br J Fam Plann 2000; 26: 73-80.

2 Blanc AK, Curtis SL, Croft TN. Monitoring contraceptive continuation: links to fertility outcomes and quality of care. Stud Fam Plann 2002; 33: 127-140.

3 Halpern V, Grimes DA, Lopez LM, Gallo MF. Strategies to improve adherence and acceptability of hormonal methods of contraception. Cochrane Database Syst Rev 2006; 1: CD004317.

4 O'Campo P, Faden RR, Gielen AC, Kass N, Anderson J. Contraceptive and sexual practices among single women with an unplanned pregnancy: partner influences. Fam Plann Perspect 1993; 25: 215-219.

5 Estabrooks C, Goel V, Thiel E, Pinfold P, Sawka C, Williams I. Decision aids: are they worth it? A systematic review. J Health Serv Res Policy 2001; 6: 170-182.

6 Chin-Quee DS, Jaonwitz B, Otterness C. Counseling tools alone do not improve method of continuation: further evidence from the decision-making tool for family planning clients and providers in Nicaragua. Contraception 2007; 76: 377-382.

7 Kim YM, Kols A, Martin A, Silva D, Rinehart W, Prammawat S, et al. Promoting informed choice: evaluation a decision-making tool for family planning clients and providers in Mexico. Int Fam Plan Perspect 2005; 31: 162-171.

8 Kim YM, Davila C, Tellez C, Kols A. Evaluation of the World Health Organization's family planning decision-making tool: improving health communication in Nicaragua. Patient Educ Couns 2007; 66: 235-242

9 French RS, Dowie J. Using decision analysis to help young people with contraceptive choices. In: Baker P, Guthrie K, Hutchinson C, Kane R (eds), Teenage Pregnancy. London, UK: RCOG Press, 2007; 133-146.

10 Chewning B, Mosena P, Wilson D, Erdman H, Potthoff S, Murphy $A$, et al. Evaluation of a computerized contraceptive decision aid for adolescent patients. Patient Educ Couns 1999; 38: 227-239.

11 Bekker H, Thornton JG, Airey CM, Connelly JB, Hewison J, Robinson $\mathrm{MB}$, et al. Informed decision making: an annotated bibliography and systematic review. Health Technol Assess 1999; 3: 1-156. ...naturally

SYLK natural personal lubricant for the alleviation of atrophic vaginitis is now included within the NHS Drug Tariff Part IX and available on an FP10.

Adopted and endorsed by a multiprofessional group investigating the use of vaginal dilators following pelvic radiotherapy, as well as members of the National Committee of the National Forum of Gynaecology Oncology Nurses (NFGON) and other relevant groups within the NHS, SYLK:

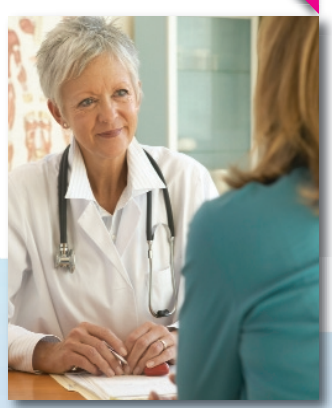

- has a non chemical base derived from an extract of the kiwi fruit plant that effectively mimics a woman's natural secretions and is the only paraben free lubricant

- has passed cytotoxicity, sensitisation and product stability tests. The pH of SYLK is controlled within 4.5 to 4.7 , to equate with the vaginal environment

- is a class 1 medical device available in one $40 \mathrm{ml}$ size, sufficient for up to 150 applications

Free samples and consumer literature are readily available from:

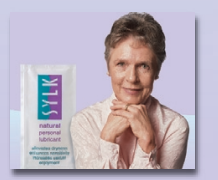
SYLK Limited FREEPOST, PO Box 340 Rickmansworth, WD3 5WD Tel: 08709506004 www.sylk.co.uk

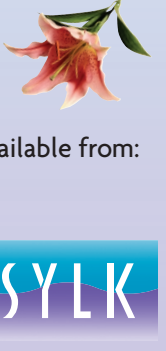

